\title{
Sistem Informasi Akademik Mahasiswa Berbasis Web Pada Akademi Kebidanan Yaspen Tugu Ibu Jakarta
}

\author{
Syamsul Bakhri \\ Program Studi Teknik Komputer, Universitas BSI Jakarta. \\ Syamsul.slb@bsi.ac.id
}

\begin{abstract}
Abstrak-Menuju insan yang cemerlang dan intelektual dapat dicapai melalui proses pendidikan dan pengajaran dalam membentuk suatu peradaban yang modern. Lembaga pendidikan baik sekolah maupun kampus dipercaya mampu menjembatani tantangan tesebut, namun dalam pelaksanaannya kita tidak dapat mengkesampingkan kemajuan teknologi yang berperan penting dalam segala aspek, termasuk bidang pendidikan. Setelah dilakukan penetilitan pada Akademi Kebidanan Yaspen Tugu Ibu, selama ini informasi akademik hanya disampaikan melalui surat edaran, selembaran kertas ataupun papan mading. Tidak hanya itu , pendistribusian Jadwal kuliah, Nilai, KRS, KHS dan Informasi pembayaran masih harus disampaikan didalam ruangan kelas. Cara ini masih sangat konvensional sehingga kurang efektif dan efesien. Perlunya dibuatkan sistem informasi akademik berbasis web dengan pendekatan waterfall dan menggunakan bahasa pemrograman HTML, PHP dan Java Script. Hal ini bertujuan agar kecepatan informasi, dapat berpengaruh dalam pengambilan keputusan mahasiswa. Hasil yang didapat dari penelitian ini adalah penyajian informasi yang lebih informatif, cepat dan akurat, akses yang tidak terbatas, 24 jam kapanpun, dimanapun. Informasi dalam bentuk digital lebih menghemat kertas / paperless.
\end{abstract}

Kata Kunci_: Perancangan Web, Informasi Akademik, Akademi Kebidanan Yaspen Tugu Ibu

\section{PENDAHULUAN}

Menuju insan yang cemerlang dan intelektual dapat dicapai melalui proses pendidikan dan pengajaran dalam membentuk suatu peradaban yang modern. Lembaga pendidikan baik sekolah maupun kampus dipercaya mampu menjembatani tantangan tesebut, namun dalam pelaksanaannya kita tidak dapat mengkesampingkan kemajuan teknologi yang berperan penting dalam segala aspek, termasuk bidang pendidikan. Demi tercapainya suatu SDM atau generasi yang berkualitas, maka kita pun perlu tanggap akan kemajuan teknologi yang berkembang pesat dan tidak akan henti-hentinya mengalami inovasi.

Begitu pun dalam bidang pendidikan tidak hanya materi maupun kurikulum saja yang perlu diperbaharui, melainkan cara pendistribusian dan penyajian informasi pun perlu disesuaikan dengan perkembangan jaman. Informasi yang cepat dan tepat merupakan nilai tambah tersendiri bagi pelayanan institusi terhadap siswa / mahasiswanya. Kegiatan akademik yang berhubungan dengan KRS, KHS, Jadwal
Kuliah, Nilai Akademik dan Status Pembayaran merupakan informasi yang sangat perlu disampaikan dengan segera, namun cara pendistribusian yang masih manual (surat edaran, papan madding dan selembaran kertas) sering kali menjadi kendala bagi institusi, karena hal tersebut masih dibatasi oleh jarak dan waktu. Terutama dalam menghadapi kendala ketidakhadiran siswa, kendala lain adalah siswa yang berada di luar kota jika informasi akademik hanya bisa didapatkan dengan mendatangi sekolah/kampus saja.

Maksud dan tujuan dibuatkan sistem informasi akademik berbasis web ini Selain meningkatkan kinerja pemanfaatan teknologi informasi dalam bidang pendidikan secara tidak langsung dapat mengotomatisasi segala bentuk pekerjaan/kegiatan akademik. Pekerjaan yang seharusnya dilakukan berulang kali, cukup dilakukan sekali saja. Hal tersebut dapat terwujud jika pihak sekolah/kampus membangun infrastruktur sistem sebagai media komunikasi efektif antara institusi dengan mahasiswa secara efektif, merancang sistem informasi akademik sebagai penunjang aktifitas belajar mengajar di Akademi Kebidanan Yaspen Tugu Ibu, menjadi solusi atas pemecahan masalah yang berhubungan dengan pendistribusian dan penyajian informasi akademik. memberikan kemudahan tanpa batas bagi siswa/mahasiswa dalam mengakses informasi akademik dimanapun dan kapanpun, memudahkan pihak kampus (admin/tata usaha/direktur) dalam mengupdate informasi seputar kebijakan/kegiatan akademik secara rutin yang akan ditampilkan di form mahasiswa.

\section{TINJAUAN PUSTAKA}

Sistem informasi diwebsite pada umumnya dituliskan dalam format HTML. Teknologi internet bekerja atas dasar web browser di komputer klien yang menampilkan data, gambar dan suara. Web browser dikenal sebagai perangkat lunak untuk menjelajah website.

\subsection{Internet}

Internet adalah salah satu bentuk media komunikasi dan informasi interaktif. Wujud internet adalah jaringan komputer yang terhubung di seluruh dunia. Internet digunakan untuk mengirim informasi antar komputer di seluruh dunia. Internet diartikan sebagai "Internet adalah 
jaringan komunikasi global yang terbuka dan menghubungkan ribuan jaringan komputer, melalui sambungan telepon umum maupun pribadi (pemerintah amupun swasta) [1].

\subsection{WWW (World Wide Web)}

www atau dikenal dengan web atau situs adalah sistem dimana informasi dalam bentuk teks, suara, gambar dan lainlain yang disimpan di server-server yang terdapat di seluruh dunia. Dokumen web dibuat dengan menggunakan format HTML (Hypertext Mark-up Language) [1].

\subsection{HTTP (Hypertext Transfer Protocol)}

HTTP adalah salah satu protocol bahasa yang digunakan untuk berkomunikasi antara server komputer dalam internet. Protokol bahasa yang lain dalam internet misalnya: telnet, news, grapher, FTP [1].

\subsection{Server Web}

Server Web adalah suatu program komputer yang mempunyai tanggung jawab atau tugas menerima permintaan HTTP dari komputer klien, yang dikenal dengan nama web browser dan melayani mereka dengan menyediakan respon HTTP berupa konten data, biasanya berupa halaman web yang terdiri dari dokumen HTML dan objek terkait seperti gambar dan lain lain [2].

\subsection{PHP (Hypertext Preprocessor)}

PHP (Hypertext Preprocessor) adalah bahasa script yang dapat ditanamkan atau disisipkan ke dalam HTML. PHP banyak dipakai untuk membuat program situs web dinamis. PHP sering juga digunakan untuk membangun sebuah CMS. PHP adalah bahasa pemrograman script server-side yang didesain untuk pengembangan web. Disebut bahasa pemrograman server side karena PHP diproses pada komputer server. Hal ini berbeda dibandingkan dengan bahasa pemrograman client-side seperti javascript yang diproses ada web browser (client)[2].

\subsection{Java Script}

Java script adalah kode untuk menyusun halaman web yang memungkinkan dijalankan disisi klien (pada browser yang digunakan pemakai). Karena dijalankan disisi klien maka javascript dapat digunakan untuk membuat tampilan lebih bersifat dinamis menampilkan jam lokal secara terus menerus, melakukan perhitungan terhadap data formulir, mengubah-ubah warna pada baris tertentu dalam suatu table dapat dikerjakan dengan menggunakan java script [3].

2.7. Model Pengembangan Perangkat Lunak Model SDLC air terjun (waterfall) sering juga disebut model sekuensial linier (sequential linear) atau hidup klasik (classic life cycle)". Model air terjun menyediakan pendekatan alur hidup perangkat lunak secara sekuensial atau berururtan dimulai dari analisis, desain, pengkodean, pengujian dan tahap pendukung (support) [4].

Berikut adalah gambar model air terjun :

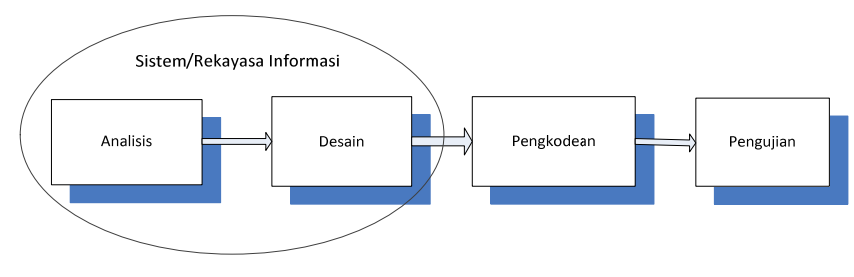

Gambar 1. Ilustrasi model waterfall

a. Analisis Kebutuhan Perangkat Lunak

Proses pengumpulan kebutuhan dilakukan secara intensif untuk mespesifikasikan kebutuhan perangkat lunak agar dapat dipahami perangkat lunak seperti apa yang dibutuhkan oleh user. Spesifikasi kebutuhan perangkat lunak pada tahap ini perlu untuk didokumentasikan.

b. Desain

Desain perangkat lunak adalah proses multi langkah yang fokus pada desain pembuatan program perangkat lunak termasuk struktur data, arsitektur perangkat lunak, representasi antar muka, dan prosedur pengodean. Tahap ini mentranslasi kebutuhan perangkat lunak dari tahap analisis kebutuhan ke representasi desain agar dapat diimplementasikan menjadi program pada tahap selanjutnya. Desain perangkat lunak yang dihasilkan pada tahap ini juga perlu didokumentasikan.

c. Pembuatan Kode Program

Desain harus ditranslasikan ke dalam program perangkat lunak. Hasil dari tahap ini adalah proram komputer sesuai dengan desain yang telah dibuat pada tahap desain.

d. Pengujian Pengujian focus pada perangkat lunak secara dari segi lojik dan fungsional dan memastikan bahwa semua bagian sudah diuji. Hal ini dilakukan untuk meminimalisir kesalahan (error) dan memastikan keluaran yang dihasilkan sesuai dengan yang diinginkan.

e. Pendukung (Support) atau pemeliharaan (Maintenance) Tidak menutup kemungkinan sebuah perangkat lunak mengalami perubahan ketika sudah dikirimkan ke user. Perubahan bisa terjadi karena adanya kesalahan yang muncul dan tidak terdeteksi saat pengujian atau perangkat lunak harus beradaptasi dengan lingkungan baru. Tahap pendukung atau pemeliharaan dapat mengulangi proses pengembangan mulai dari analisis spesifikasi untuk perubahan perangkat lunak yang sudah ada, tapi tidak untuk membuat perangkat lunak baru. 


\section{METODE PENELITIAN}

Dalam pencarian data penulis menggunkan model pengembangan perangkat lunak dan pengumpulan data yang penulis gunakan adalah:

A. Model Pengembangan Perangkat Lunak

Model pengembangan sistem yang di gunakan oleh penulis adalah metode pengembangan sistem dengan model waterfall. Model SDLC air terjun (Waterfall) sering juga disebut model sekuensi linier (sequential linear) atau alur hidup klasik (classic life cycle) [4]. Model air terjun menyediakan pendekatan alur hidup perangkat lunak secara sekuensial atau terurut dimulai dari analisis, desain, pengkodean dan pengujian.

Penjelasan tahapan demi tahapan:

\section{Analisis}

Penulis menuangkan semua yang berkaitan dengan mahasiswa dalam bentuk aplikasi (software) dibuatkan khusus untuk bisa menginput data mahasiwa, data dosen, data nilai, jadwal kuliah, dan status pembayaran. Mahasiswa dapat melihat langsung nilai, jadwal kuliah, dan status pembayaran di halaman student. Selain itu admin dapat menambahkan/mengedit atau menghapus data di halaman admin.

2. Desain Perangkat Lunak

Proses perancangan sistem ini difokuskan pada empat atribut, yaitu struktur data, arsitektur perangkat lunak, representasi antarmuka dan detail (algoritma) prosedural. Untuk menggambarkan database menggunakan ERD dan LRS serta spesifikasi file.

3. Pembuatan kode Program

Pada tahap ini, perancangan perangkat lunak direalisasikan sebagai serangkaian program atau unit program. Software yang digunakan dalam pembuatan kode program menggunakan dreamweaver CS5.

\section{Pengujian}

Pengujian fokus pada perangkat lunak dari segi logic dan fungsional dan memastikan bahwa semua bagian sudah diuji. Pengujian dengan menggunakan black box testing.

B. Teknik pengumpulan Data

Teknik pengumpulan data yang digunakan oleh penulis dalam melakukan pengumpulan data untuk pembuatan TA adalah :

\section{Observasi}

Pengamatan dilakukan secara langsung di Akademi Kebidanan Yaspen Tugu Ibu, dengan mengumpulkan data-data akademik yang berhubungan dengan penelitian, agar sistem informasi akademik berjalan sebagaimana mestinya.

\section{Wawancara}

Wawancara dilakukan secara tanya-jawab kepada bagian evaluasi atau akademik, seperti apakah proses sistem berjalan selama ini, agar dapat disesuaikan dengan sistem informasi akademik sehingga sesuai dengan kebutuhan.

\section{Studi Pustaka}

Studi pustaka dilakukan dengan mencari buku referensi seperti studi literatur dengan mempelajari buku-buku atau bacaan yang relevan dengan masalah yang sedang diteliti, baik melalui perpustakaan maupun dari jurnal atau sumber lain seperti internet. Agar hasil penelitian dapat benarbenar sesuai dengan kebutuhan pengguna, selain itu digunakan pula

\section{HASIL DAN PEMBAHASAN}

A. Implementasi

Implementasi Rancangan Antar Muka pada Sistem Informasi Akademik Mahasiswa berdasarkan hasil rancangan antar muka.

1. Halaman Admin/ Login

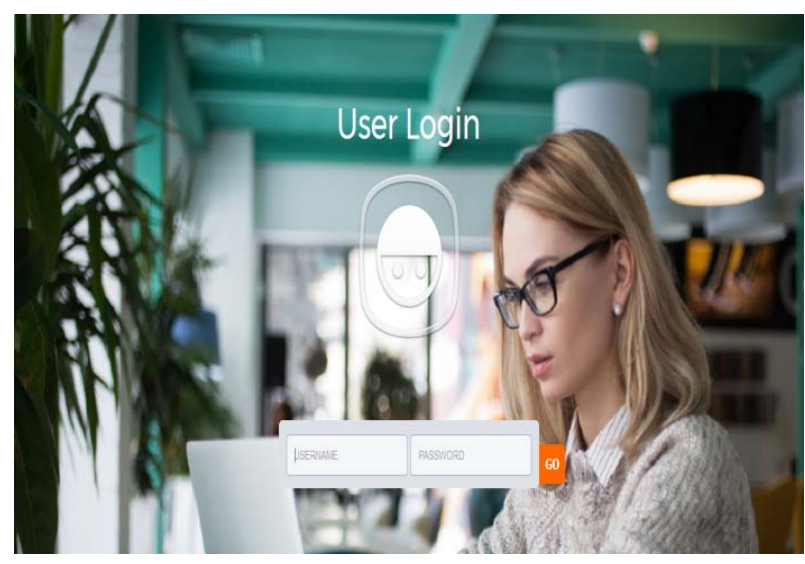

Gambar 2.Halaman Admin/ Login

\section{Halaman Admin/ Home}

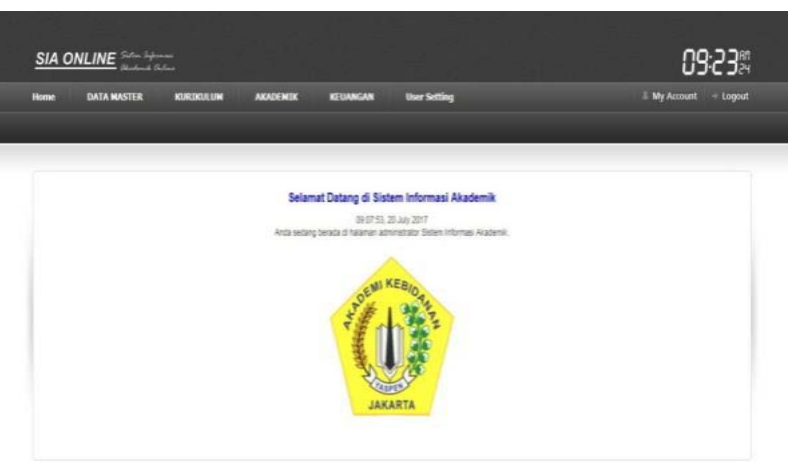

Gambar 24.Halaman Admin/ Login 
3. Halaman Admin/ Input Data Mahasiswa
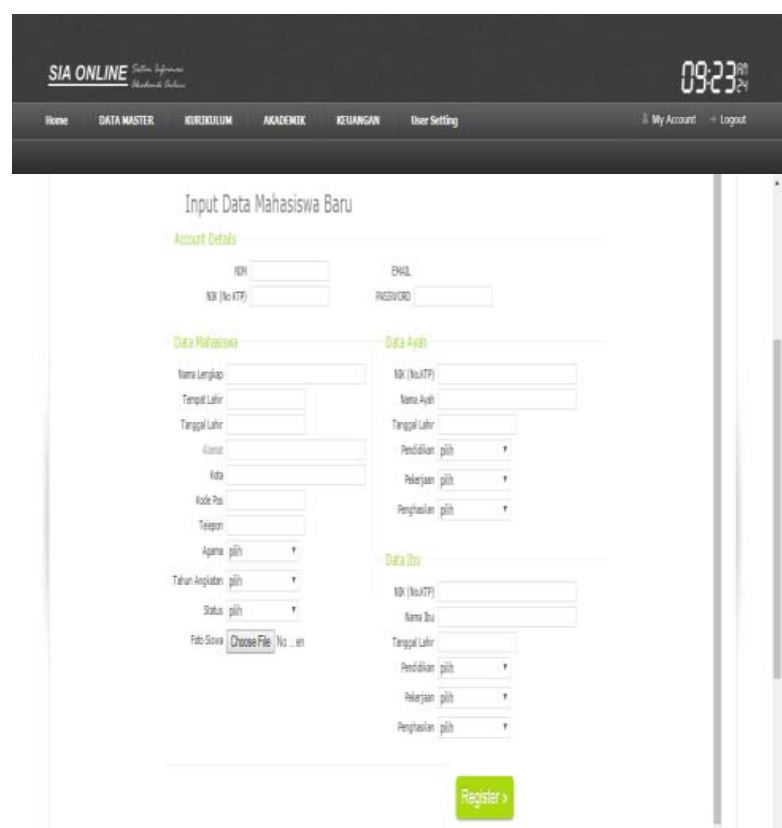

Gambar 25.Halaman Admin/ Input Data Mahasiswa

4. Halaman Admin/ Input Data Dosen
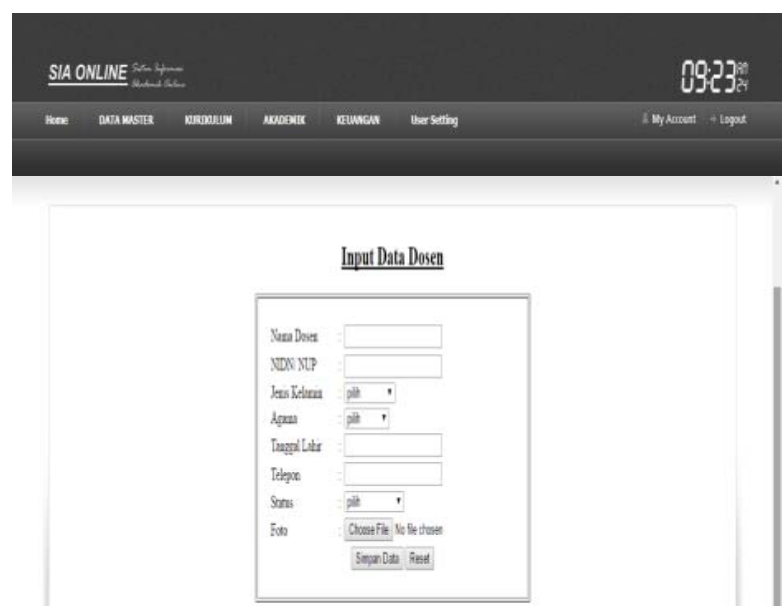

Gambar 26.Halaman Admin/ Input Data Dosen

\section{Halaman Admin/ Lihat Data Dosen}

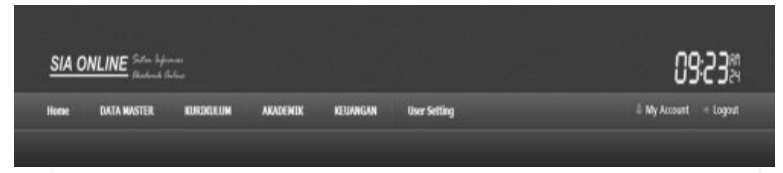

Data Dosen Pengajar

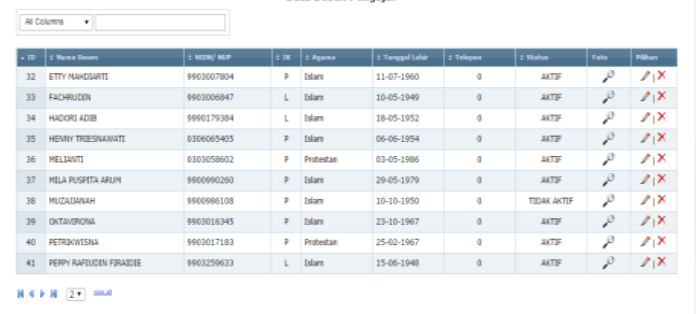

Gambar 27.Halaman Admin/ Lihat Data Dosen

6. Halaman Admin/ Input Mata Kuliah

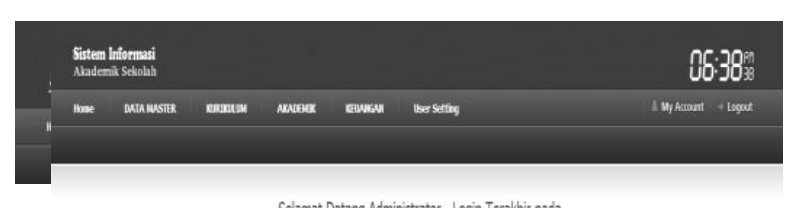

Selamat Datang Administrator, Login Terakhir pada

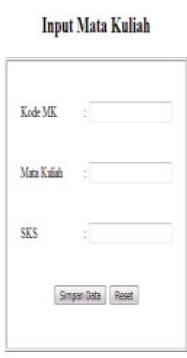

Oinivasiat

Gambar 28..Halaman Admin/ Input Mata Kuliah

7. Halaman Admin/Lihat Mata Kuliah

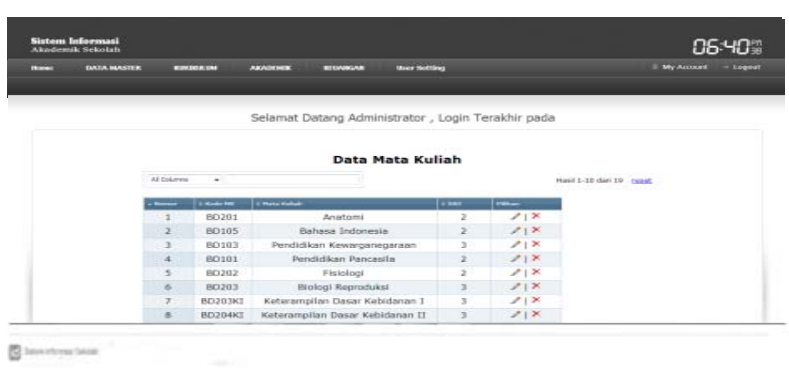

Gambar 29.Halaman Admin/ Lihat Mata Kuliah 
8. Halaman Admin/ Input Jadwal Kuliah

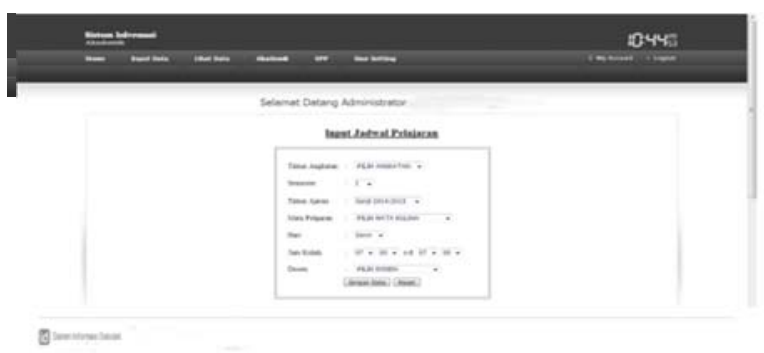

Gambar 30.Halaman Admin/ Input Jadwal Kuliah

9. Halaman Admin/ Lihat Data Mahasiswa

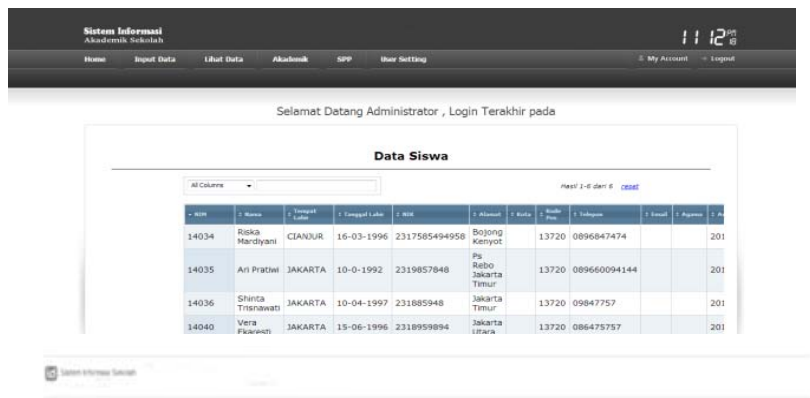

Gambar 31. Halaman Admin/ Liat Data Mahasiswa

\section{Halaman Admin/ Lihat Data Mata Kuliah}

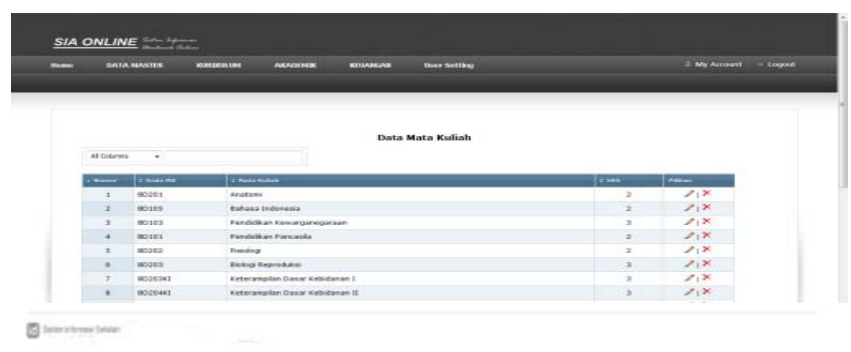

Gambar 32.Halaman Admin/ Lihat Data Mata Kuliah

11. Halaman Admin/ Input SPP Mahasiswa

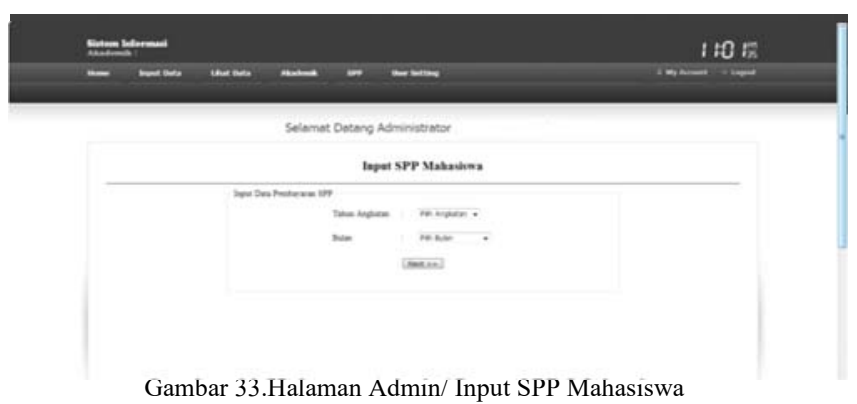

Gambar 33.Halaman Admin/ Input SPP Mahasiswa

\section{Halaman Admin/Liat SPP Mahasiswa}

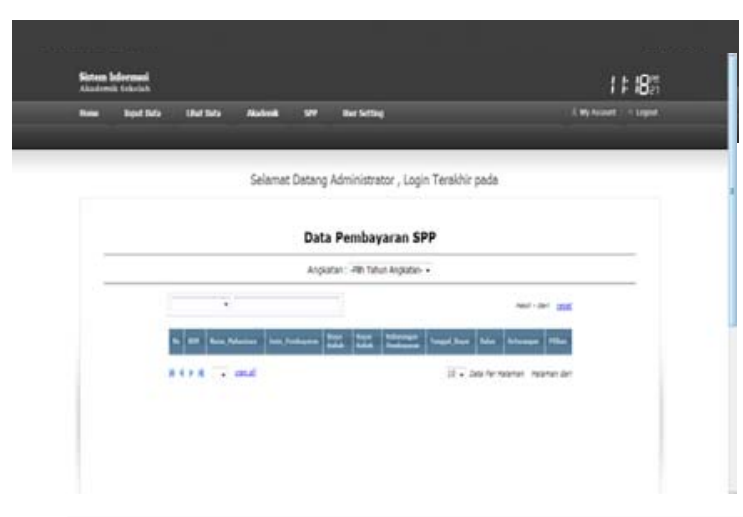

Qiminave

Gambar 34.Halaman Admin/ Liat SPP Mahasiswa

13. Halaman Admin/ Lihat Data Mahasiswa
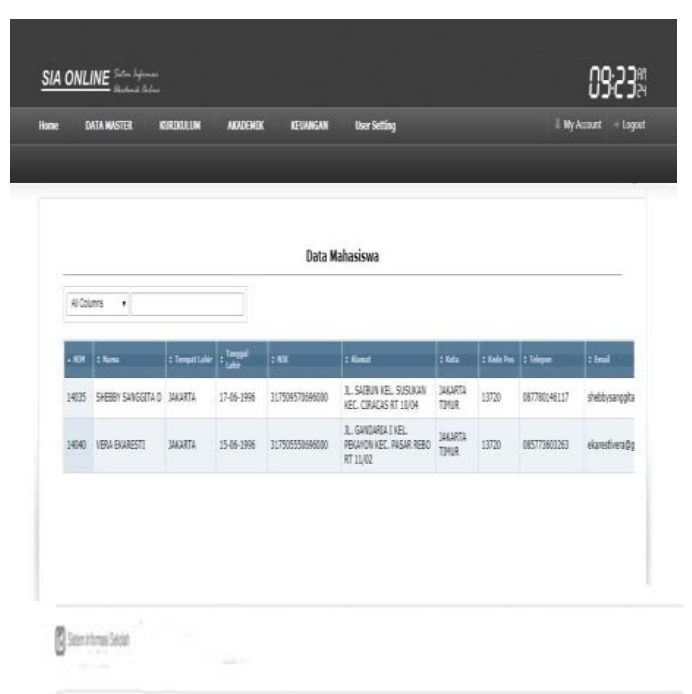

Gambar 35.Halaman Admin/ Lihat Data Mahasiswa

14. Halaman Admin/ Setting Biaya

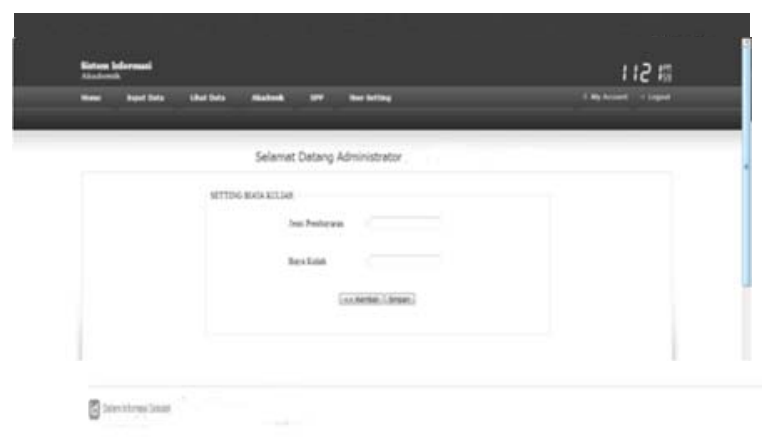

Gambar 36.Halaman Admin/ Setting Biaya 
15. Halaman Admin/ Input KRS Angkatan

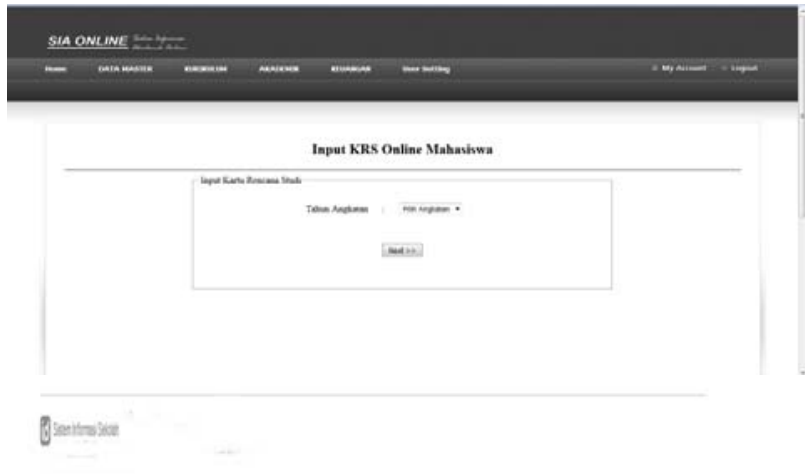

Gambar 37.Halaman Admin/ Input KRS Angkatan

16. Halaman Admin/ Input KRS Mahasiswa

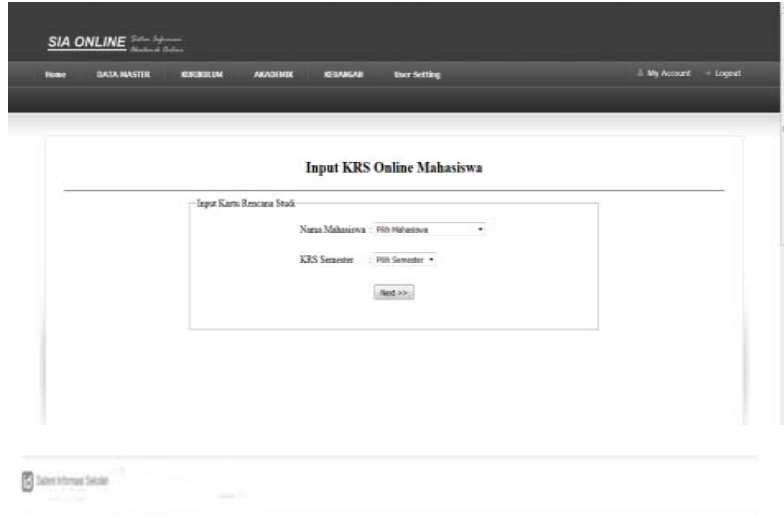

Gambar 38. Halaman Admin/ Input KRS Mahasiswa

17. Halaman Admin/Input Detail KRS

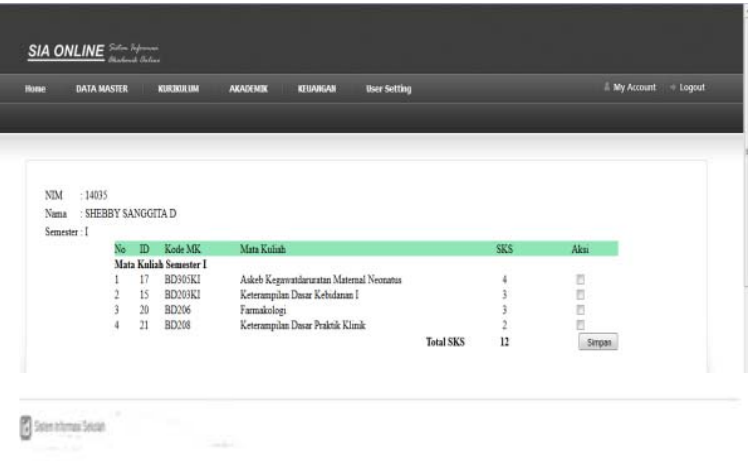

Gambar 39.Halaman Admin/ Input Detail KRS
18. Halaman Admin/ Input Nilai Angkatan

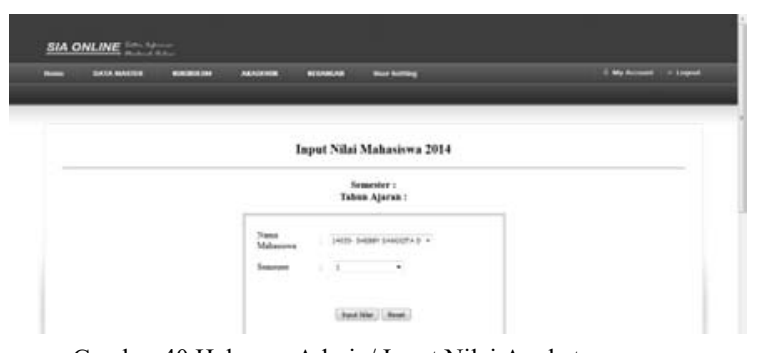

Gambar 40.Halaman Admin/ Input Nilai Angkatan

19. Halaman Admin/Input Nilai Mahasiswa

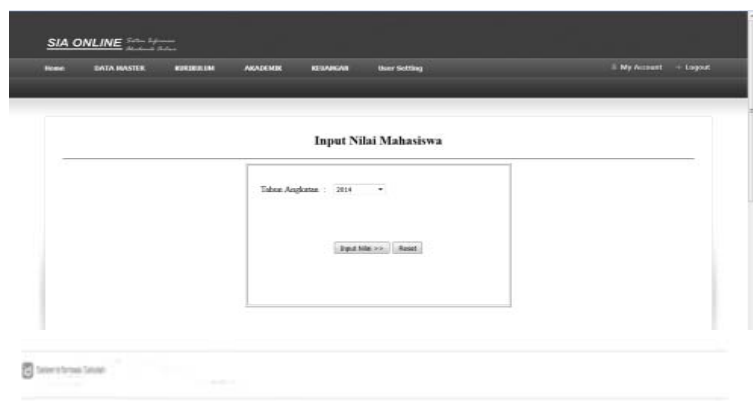

Gambar 41.Halaman Admin/ Input Nilai Mahasiswa

20. Halaman Admin/ Input Nilai Mata Kuliah

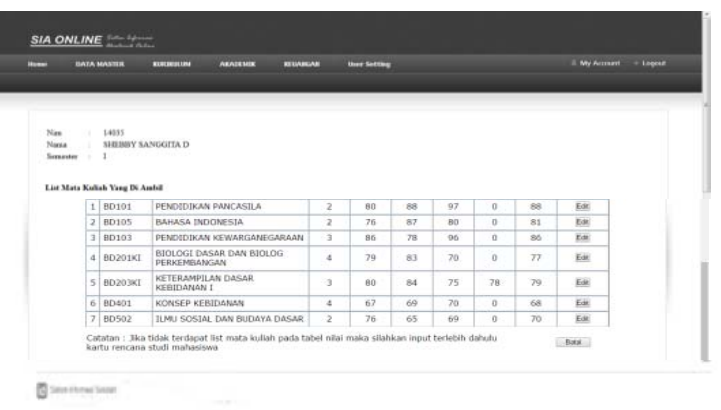

Gambar 42.Halaman Admin/ Input Nilai Mata Kuliah

21. Halaman Admin/ Input Detail Nilai

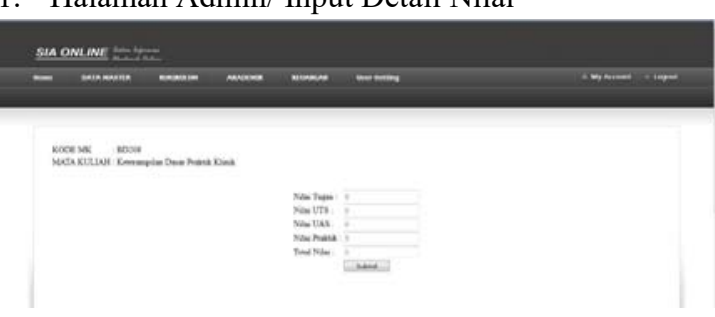

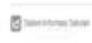

Gambar 43.Halaman Admin/ Input Detail Nilai 


\section{Halaman User/Login}

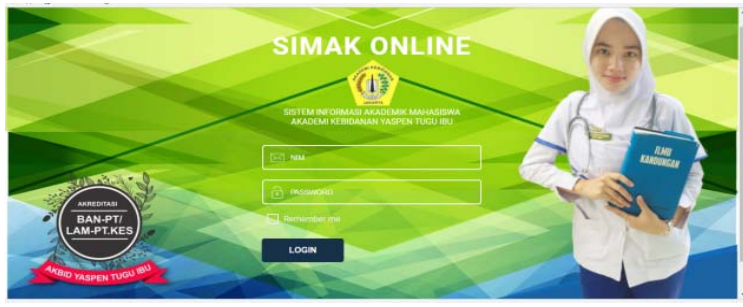

Gambar 44.Halaman User/ Login

\section{Halaman User/ Home}

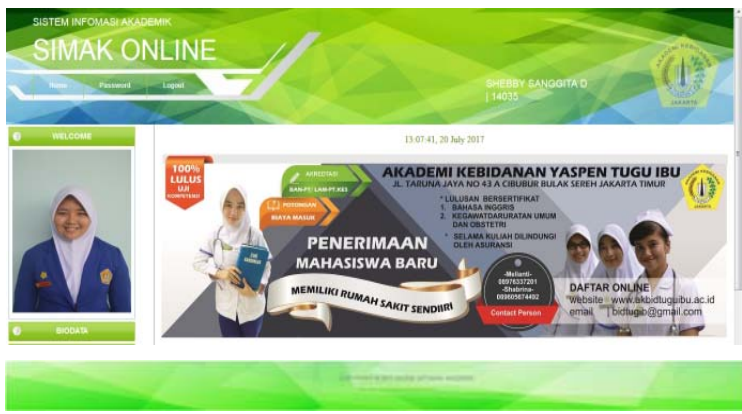

Gambar 45.Halaman User/ Home

\section{Halaman User/ Biodata}
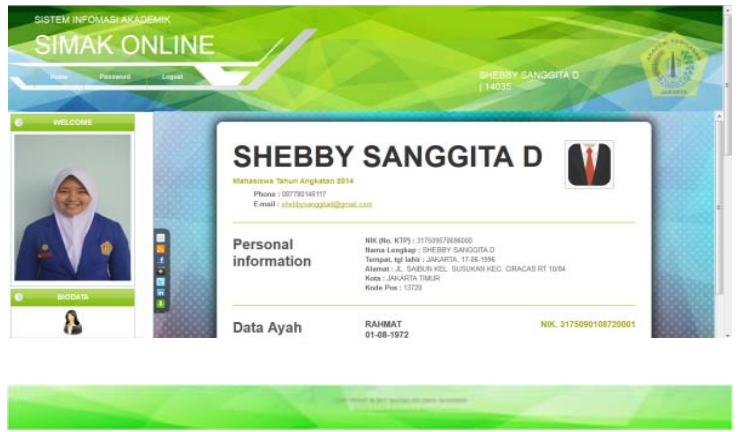

Gambar 46.Halaman User/ Biodata

\section{Halaman User/ Lihat Nilai}

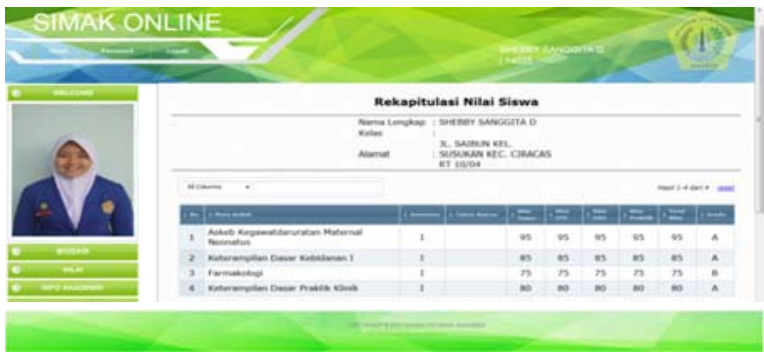

Gambar 47.Halaman User/ Lihat Nilai
26. Halaman User/ Jadwal Kuliah
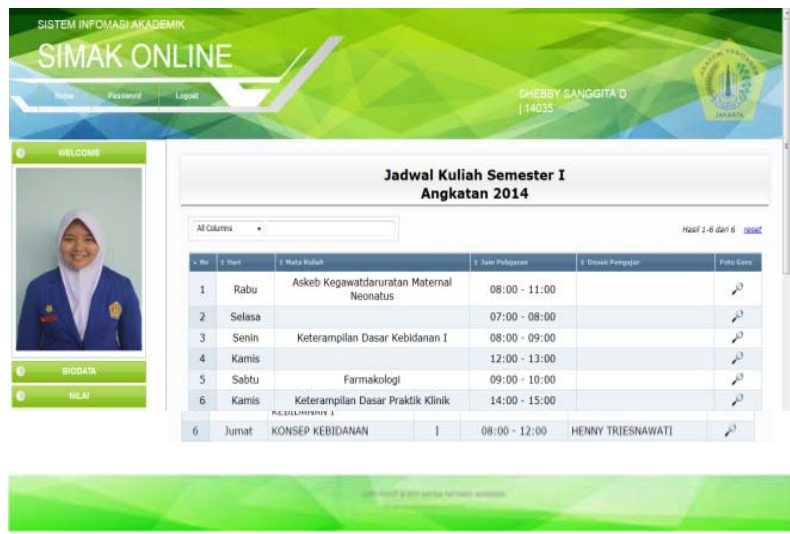

Gambar 48. Halaman User/ Jadwal Kuliah

27. Halaman User/ Teman Sekelas

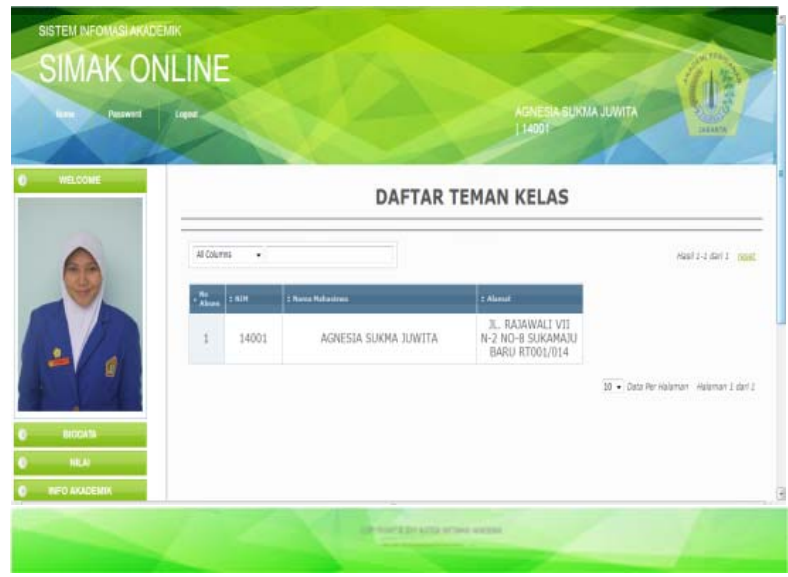

Gambar 49.Halaman User/ Teman Sekelas

28. Halaman User/ KRS ONLINE

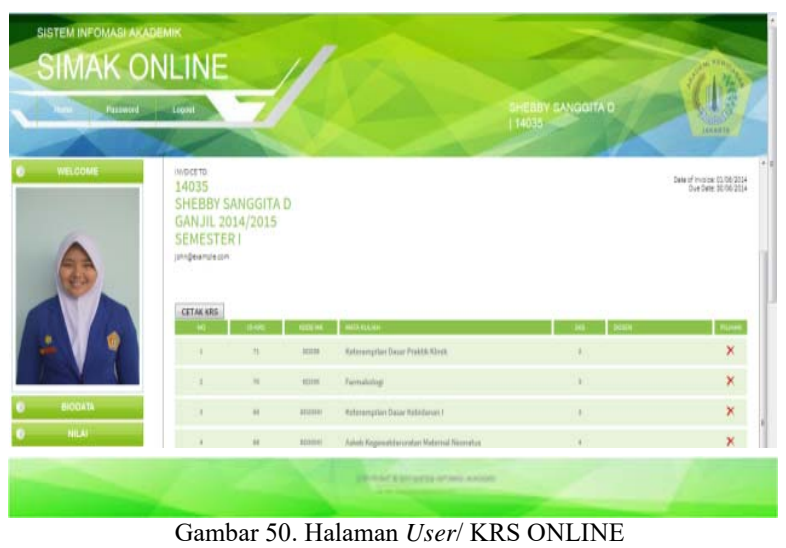




\section{Halaman User/ KHS ONLINE}

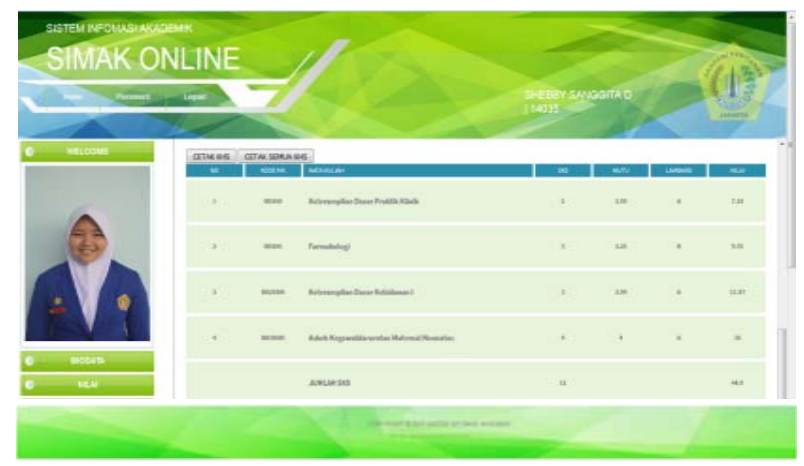

Gambar 51.Halaman User/ KHS ONLINE

30. Halaman User/ Status Pembayaran SPP

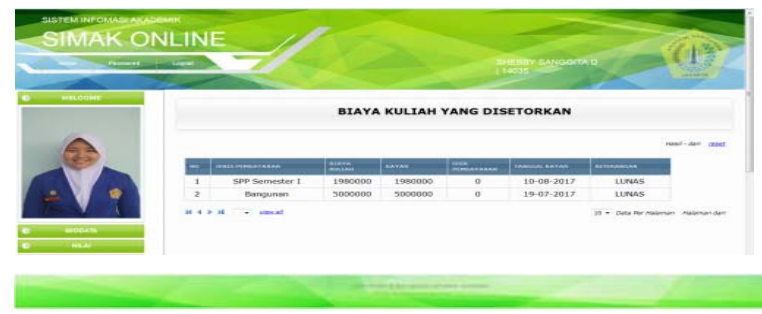

Gambar 52. Halaman User/ Status Pembayaran SPP

\section{Halaman User/ Ganti Password}

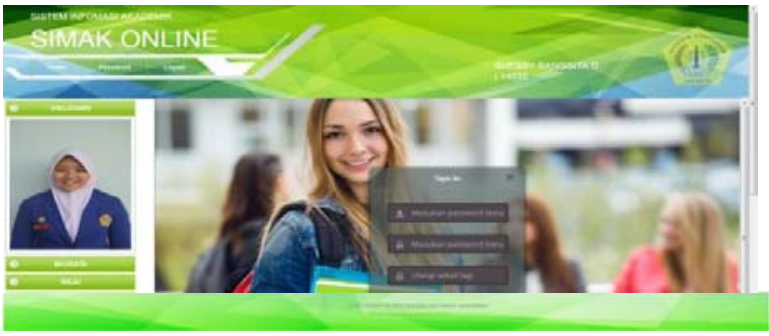

Gambar 53.Halaman User/ Ganti Password

\section{PENGUJIAN UNIT}

Pengujian terhadap program yang dibuat menggunakan blackbox testing yang fokus terhadap proses masukan dan keluaran program.

\section{A. Pengujian terhadap form Login Admin}

Tabel1

Hasil Pengujian Blac Box Testing Login Admin

\begin{tabular}{|c|l|l|l|c|c|}
\hline $\begin{array}{c}\text { No } \\
\cdot\end{array}$ & \multicolumn{1}{|c|}{$\begin{array}{c}\text { Skenario } \\
\text { pengujian }\end{array}$} & \multicolumn{1}{|c|}{ Test case } & \multicolumn{1}{|c|}{$\begin{array}{c}\text { Hasil yang } \\
\text { diharapkan }\end{array}$} & $\begin{array}{c}\text { Hasil } \\
\text { pengujian }\end{array}$ & $\begin{array}{c}\text { Kesimp } \\
\text { ulan }\end{array}$ \\
\hline 1. & $\begin{array}{l}\text { Username dan } \\
\text { password tidak } \\
\text { disi kemudian } \\
\text { klik tombol GO }\end{array}$ & $\begin{array}{l}\text { Username: } \\
\text { (kosong) } \\
\text { Password: } \\
\text { (kosong) }\end{array}$ & $\begin{array}{l}\text { Sistem akan } \\
\text { menolak akses } \\
\text { user dan } \\
\text { menampilkan } \\
\text { "LOGIN } \\
\text { GAGAL". }\end{array}$ & $\begin{array}{l}\text { Sesuai } \\
\text { harapan }\end{array}$ & Valid \\
& & & & & \\
\hline
\end{tabular}

\begin{tabular}{|c|c|c|c|c|c|}
\hline 2. & $\begin{array}{l}\text { Mengetikkan } \\
\text { username dan } \\
\text { password tidak } \\
\text { diisi atau } \\
\text { kosong } \\
\text { kemudian klik } \\
\text { tombol } G O\end{array}$ & $\begin{array}{l}\text { Username : } \\
\text { nadia } \\
\text { Password : } \\
\text { (kosong) }\end{array}$ & $\begin{array}{l}\text { Sistem akan } \\
\text { menolak akses } \\
\text { user dan } \\
\text { menampilkan } \\
\text { "LOGIN } \\
\text { GAGAL". }\end{array}$ & $\begin{array}{l}\text { Sesuai } \\
\text { harapan }\end{array}$ & Valid \\
\hline 3. & $\begin{array}{l}\text { Mengetikan } \\
\text { Username } \\
\text { kosong dan } \\
\text { password diisi } \\
\text { dengan benar } \\
\text { kemudian klik } \\
\text { tombol GO }\end{array}$ & $\begin{array}{l}\text { Username: } \\
\text { (kosong) } \\
\text { Password: } \\
\text { kamu }\end{array}$ & $\begin{array}{l}\text { Sistem akan } \\
\text { menolak akses } \\
\text { user dan } \\
\text { menampilkan } \\
\text { "LOGIN } \\
\text { GAGAL". }\end{array}$ & $\begin{array}{l}\text { Sesuai } \\
\text { harapan }\end{array}$ & Valid \\
\hline 4. & $\begin{array}{l}\text { Mengetikkan } \\
\text { username dan } \\
\text { password } \\
\text { dengan data } \\
\text { yang benar } \\
\text { kemudian klik } \\
\text { tombol GO }\end{array}$ & $\begin{array}{l}\text { Username: } \\
\text { nadia } \\
\text { Password: } \\
\text { kamu }\end{array}$ & $\begin{array}{l}\text { Sistem } \\
\text { menerima akses } \\
\text { login dan } \\
\text { kemudian } \\
\text { langsung } \\
\text { menampilkan } \\
\text { menu utama } \\
\text { Administrator. }\end{array}$ & $\begin{array}{c}\text { Sesuai } \\
\text { harapan }\end{array}$ & Valid \\
\hline
\end{tabular}

B. Pengujian terhadap form Input Data Mahasiswa Baru

Tabel 2

Hasil Pengujian Black Box Testing Halaman Input Data Mahasiswa Baru

\begin{tabular}{|c|c|c|c|c|c|}
\hline No & $\begin{array}{l}\text { Skenario } \\
\text { Pengujian }\end{array}$ & Test Case & $\begin{array}{l}\text { Hasil yang } \\
\text { diharapan }\end{array}$ & $\begin{array}{l}\text { Hasil } \\
\text { Penguj } \\
\text { ian }\end{array}$ & $\begin{array}{l}\text { Kesi } \\
\text { mpul } \\
\text { an }\end{array}$ \\
\hline 1. & $\begin{array}{l}\text { Mengosongkan } \\
\text { form NIM saat } \\
\text { mengklik } \\
\text { tombol register }\end{array}$ & $\begin{array}{l}\text { NIM: } \\
\text { Kosong }\end{array}$ & $\begin{array}{l}\text { Sistem akan } \\
\text { menolak akses } \\
\text { penyimpanan } \\
\text { dan } \\
\text { menampilkan } \\
\text { pesan/notifikasi } \\
\text { "NIM masih } \\
\text { kosong" }\end{array}$ & $\begin{array}{l}\text { Sesuai } \\
\text { harapa } \\
\mathrm{n}\end{array}$ & Valid \\
\hline 2. & $\begin{array}{l}\text { Mengetikan } \\
\text { form NIM diisi } \\
\text { dengan } \\
\text { huruf/abjad }\end{array}$ & $\begin{array}{l}\text { NIM : } \\
\text { ABCDEFG } \\
\text { (salah) }\end{array}$ & $\begin{array}{l}\text { Sistem akan } \\
\text { menolak dan } \\
\text { mengunci } \\
\text { ketika user } \\
\text { memasukan } \\
\text { karakter yang } \\
\text { salah berupa } \\
\text { huruf/abjad } \\
\text { serta } \\
\text { menampilkan } \\
\text { pesan/notifikasi } \\
\text { "Form hanya } \\
\text { disi dengan } \\
\text { karakter 0-9 } \\
\text { nomor/angka" }\end{array}$ & $\begin{array}{l}\text { Sesuai } \\
\text { harapa } \\
\mathrm{n}\end{array}$ & Valid \\
\hline 3. & $\begin{array}{l}\text { Mengetikan } \\
\text { form: NIM diisi } \\
\text { dengan } \\
\text { angka/numerik }\end{array}$ & $\begin{array}{l}\text { NIM : } \\
14035 \\
\text { (benar) }\end{array}$ & $\begin{array}{l}\text { Sistem akan } \\
\text { menerima akses } \\
\text { penginputan } \\
\text { dan } \\
\text { menampilkan } \\
\text { karakter yang } \\
\text { diinput } \\
\text { kemudian form } \\
\text { dapat di isi } \\
\text { dengan data } \\
\text { yang benar }\end{array}$ & $\begin{array}{l}\text { Sesuai } \\
\text { harapa } \\
\mathrm{n}\end{array}$ & Valid \\
\hline
\end{tabular}




\begin{tabular}{|c|c|c|c|c|c|}
\hline 4. & $\begin{array}{l}\text { Mengosongkan } \\
\text { form NIK } \\
\text { Mahasiswa/ } \\
\text { Ayah/Ibu saat } \\
\text { mengklik } \\
\text { tombol register }\end{array}$ & $\begin{array}{l}\text { NIK: } \\
\text { Kosong }\end{array}$ & $\begin{array}{l}\text { Sistem akan } \\
\text { menolak akses } \\
\text { penyimpanan } \\
\text { dan } \\
\text { menampilkan } \\
\text { pesan/notifikasi } \\
\text { "NIKmasih } \\
\text { kosong" }\end{array}$ & $\begin{array}{l}\text { Sesuai } \\
\text { harapa } \\
\mathrm{n}\end{array}$ & Valid \\
\hline 5. & $\begin{array}{l}\text { Mengetikan } \\
\text { form NIK } \\
\text { Mahasiswa/ } \\
\text { Ayah/Ibu diisi } \\
\text { dengan huruf } \\
\text { /abjad }\end{array}$ & $\begin{array}{l}\text { NIK : } \\
\text { ABCDEFG } \\
\text { (salah) }\end{array}$ & $\begin{array}{l}\text { Sistem akan } \\
\text { menolak dan } \\
\text { mengunci } \\
\text { ketika user } \\
\text { memasukan } \\
\text { karakter yang } \\
\text { salah berupa } \\
\text { huruf/abjad } \\
\text { serta } \\
\text { menampilkan } \\
\text { pesan/notifikasi } \\
\text { "Form hanya } \\
\text { disi dengan } \\
\text { karakter 0-9 } \\
\text { nomor/angka" }\end{array}$ & $\begin{array}{l}\text { Sesuai } \\
\text { harapa } \\
\mathrm{n}\end{array}$ & Valid \\
\hline 6. & $\begin{array}{l}\text { Mengetikan } \\
\text { form NIK } \\
\text { Mahasiswa/ } \\
\text { Ayah/Ibu diisi } \\
\text { dengan angka } \\
\text { /numerik }\end{array}$ & $\begin{array}{l}\text { NIK : } \\
123456 \\
\text { (benar) }\end{array}$ & $\begin{array}{l}\text { Sistem akan } \\
\text { menerima akses } \\
\text { penginputan } \\
\text { dan } \\
\text { menampilkan } \\
\text { karakter yang } \\
\text { diinput } \\
\text { kemudian form } \\
\text { dapat di isi } \\
\text { dengan data } \\
\text { yang benar }\end{array}$ & $\begin{array}{l}\text { Sesuai } \\
\text { harapa } \\
n\end{array}$ & Valid \\
\hline 6. & $\begin{array}{l}\text { Mengosongkan } \\
\text { form Nama } \\
\text { Lengkap } \\
\text { Mahasiswa/Aya } \\
\mathrm{h} \\
\text { /Ibu saat } \\
\text { mengklik } \\
\text { tombol register }\end{array}$ & $\begin{array}{l}\text { Nama } \\
\text { Kosong }\end{array}$ & $\begin{array}{l}\text { Sistem akan } \\
\text { menolak akses } \\
\text { penyimpanan } \\
\text { dan } \\
\text { menampilkan } \\
\text { pesan/notifikasi } \\
\text { "Nama masih } \\
\text { kosong" }\end{array}$ & $\begin{array}{l}\text { Sesuai } \\
\text { harapa } \\
\mathrm{n}\end{array}$ & Valid \\
\hline 7. & $\begin{array}{l}\text { Mengetikan } \\
\text { form Nama } \\
\text { Lengkap } \\
\text { Mahasiswa/Aya } \\
\mathrm{h} \\
\text { /Ibu diisi } \\
\text { dengan } \\
\text { angka/numerik }\end{array}$ & $\begin{array}{l}\text { Nama } \\
\text { Lengkap: } \\
123456 \\
\text { (salah) }\end{array}$ & $\begin{array}{l}\text { Sistem akan } \\
\text { menolak ketika } \\
\text { user } \\
\text { memasukan } \\
\text { karakter yang } \\
\text { salah berupa } \\
\text { angka/numerik } \\
\text { serta } \\
\text { menampilkan } \\
\text { pesan/notifikasi } \\
\text { "Form hanya } \\
\text { disi dengan } \\
\text { karakter a-z } \\
\text { huruf/abjad }\end{array}$ & $\begin{array}{l}\text { Sesuai } \\
\text { harapa } \\
n\end{array}$ & Valid \\
\hline 8. & $\begin{array}{l}\text { Mengetikan } \\
\text { form Nama } \\
\text { Lengkap } \\
\text { Mahasiswa/ } \\
\text { Ayah } \\
\text { /Ibu diisi } \\
\text { dengan } \\
\text { huruf/abjad }\end{array}$ & $\begin{array}{l}\text { Nama } \\
\text { Lengkap: } \\
\text { Ari Pratiwi } \\
\text { (benar) }\end{array}$ & $\begin{array}{l}\text { Sistem akan } \\
\text { menerima akses } \\
\text { penginputan } \\
\text { dan } \\
\text { menampilkan } \\
\text { karakter yang } \\
\text { diinput } \\
\text { kemudian form } \\
\text { dapat di isi } \\
\text { dengan data } \\
\text { yang benar }\end{array}$ & $\begin{array}{l}\text { Sesuai } \\
\text { harapa } \\
\mathrm{n}\end{array}$ & Valid \\
\hline
\end{tabular}

\begin{tabular}{|c|c|c|c|c|c|}
\hline 9. & $\begin{array}{l}\text { Mengosongkan } \\
\text { form Tempat } \\
\text { Lahir saat } \\
\text { mengklik } \\
\text { tombol register }\end{array}$ & $\begin{array}{l}\text { Tempat } \\
\text { Lahir: } \\
\text { Kosong }\end{array}$ & $\begin{array}{l}\text { Sistem akan } \\
\text { menolak akses } \\
\text { penyimpanan } \\
\text { dan } \\
\text { menampilkan } \\
\text { pesan/notifikasi } \\
\text { "Tempat lahir } \\
\text { masih kosong" }\end{array}$ & $\begin{array}{l}\text { Sesuai } \\
\text { harapa } \\
n\end{array}$ & Valid \\
\hline 10. & $\begin{array}{l}\text { Mengetikan } \\
\text { form Tempat } \\
\text { Lahir diisi } \\
\text { dengan } \\
\text { angka/numerik }\end{array}$ & $\begin{array}{l}\text { Tempat } \\
\text { Lahir: } \\
1213232 \\
\text { (salah) }\end{array}$ & $\begin{array}{l}\text { Sistem akan } \\
\text { menolak ketika } \\
\text { user } \\
\text { memasukan } \\
\text { karakter yang } \\
\text { salah berupa } \\
\text { angka/numerik } \\
\text { serta } \\
\text { menampilkan } \\
\text { pesan/notifikasi } \\
\text { "Form hanya } \\
\text { disi dengan } \\
\text { karakter a-z } \\
\text { huruf/abjad" }\end{array}$ & $\begin{array}{l}\text { Sesuai } \\
\text { harapa } \\
\mathrm{n}\end{array}$ & Valid \\
\hline 11. & $\begin{array}{l}\text { Mengetikan } \\
\text { form Tempat } \\
\text { Lahir diisi } \\
\text { dengan } \\
\text { huruf/abjad }\end{array}$ & $\begin{array}{l}\text { Tempat } \\
\text { Lahir: } \\
\text { Jakarta } \\
\text { (benar) }\end{array}$ & $\begin{array}{l}\text { Sistem akan } \\
\text { menerima akses } \\
\text { penginputan } \\
\text { dan } \\
\text { menampilkan } \\
\text { karakter yang } \\
\text { diinput } \\
\text { kemudian form } \\
\text { dapat di isi } \\
\text { dengan data } \\
\text { yang benar }\end{array}$ & $\begin{array}{l}\text { Sesuai } \\
\text { harapa } \\
n\end{array}$ & Valid \\
\hline 12. & $\begin{array}{l}\text { Mengosongkan } \\
\text { form Kota saat } \\
\text { mengklik } \\
\text { tombol register }\end{array}$ & $\begin{array}{l}\text { Kota: } \\
\text { Kosong }\end{array}$ & $\begin{array}{l}\text { Sistem akan } \\
\text { menolak akses } \\
\text { penyimpanan } \\
\text { dan } \\
\text { menampilkan } \\
\text { pesan/notifikasi } \\
\text { "Kota masih } \\
\text { kosong" }\end{array}$ & $\begin{array}{l}\text { Sesuai } \\
\text { harapa } \\
n\end{array}$ & Valid \\
\hline 13. & $\begin{array}{l}\text { Mengetikan } \\
\text { form Kota diisi } \\
\text { dengan } \\
\text { angka/numerik }\end{array}$ & $\begin{array}{l}\text { Kota: } \\
1213232 \\
\text { (salah) }\end{array}$ & $\begin{array}{l}\text { Sistem akan } \\
\text { menolak ketika } \\
\text { user } \\
\text { memasukan } \\
\text { karakter yang } \\
\text { salah berupa } \\
\text { angka/numerik } \\
\text { serta } \\
\text { menampilkan } \\
\text { pesan/notifikasi } \\
\text { "Form hanya } \\
\text { disi dengan } \\
\text { karakter a-z } \\
\text { huruf/abjad" }\end{array}$ & $\begin{array}{l}\text { Sesuai } \\
\text { harapa } \\
n\end{array}$ & Valid \\
\hline 14. & $\begin{array}{l}\text { Mengetikan } \\
\text { form Kota diisi } \\
\text { dengan } \\
\text { huruf/abjad }\end{array}$ & $\begin{array}{l}\text { Kota: } \\
\text { Depok } \\
\text { (benar) }\end{array}$ & $\begin{array}{l}\text { Sistem akan } \\
\text { menerima dan } \\
\text { form dapat di isi } \\
\text { dengan data } \\
\text { yang benar }\end{array}$ & $\begin{array}{l}\text { Sesuai } \\
\text { harapa } \\
\mathrm{n}\end{array}$ & Valid \\
\hline 15. & $\begin{array}{l}\text { Mengosongkan } \\
\text { form Kode Pos } \\
\text { saat mengklik } \\
\text { tombol register }\end{array}$ & $\begin{array}{l}\text { Kode Pos: } \\
\text { Kosong }\end{array}$ & $\begin{array}{l}\text { Sistem akan } \\
\text { menolak akses } \\
\text { penyimpanan } \\
\text { dan } \\
\text { menampilkan } \\
\text { pesan/notifikasi } \\
\text { "Kode pos } \\
\text { masih kosong" }\end{array}$ & $\begin{array}{l}\text { Sesuai } \\
\text { harapa } \\
n\end{array}$ & Valid \\
\hline
\end{tabular}




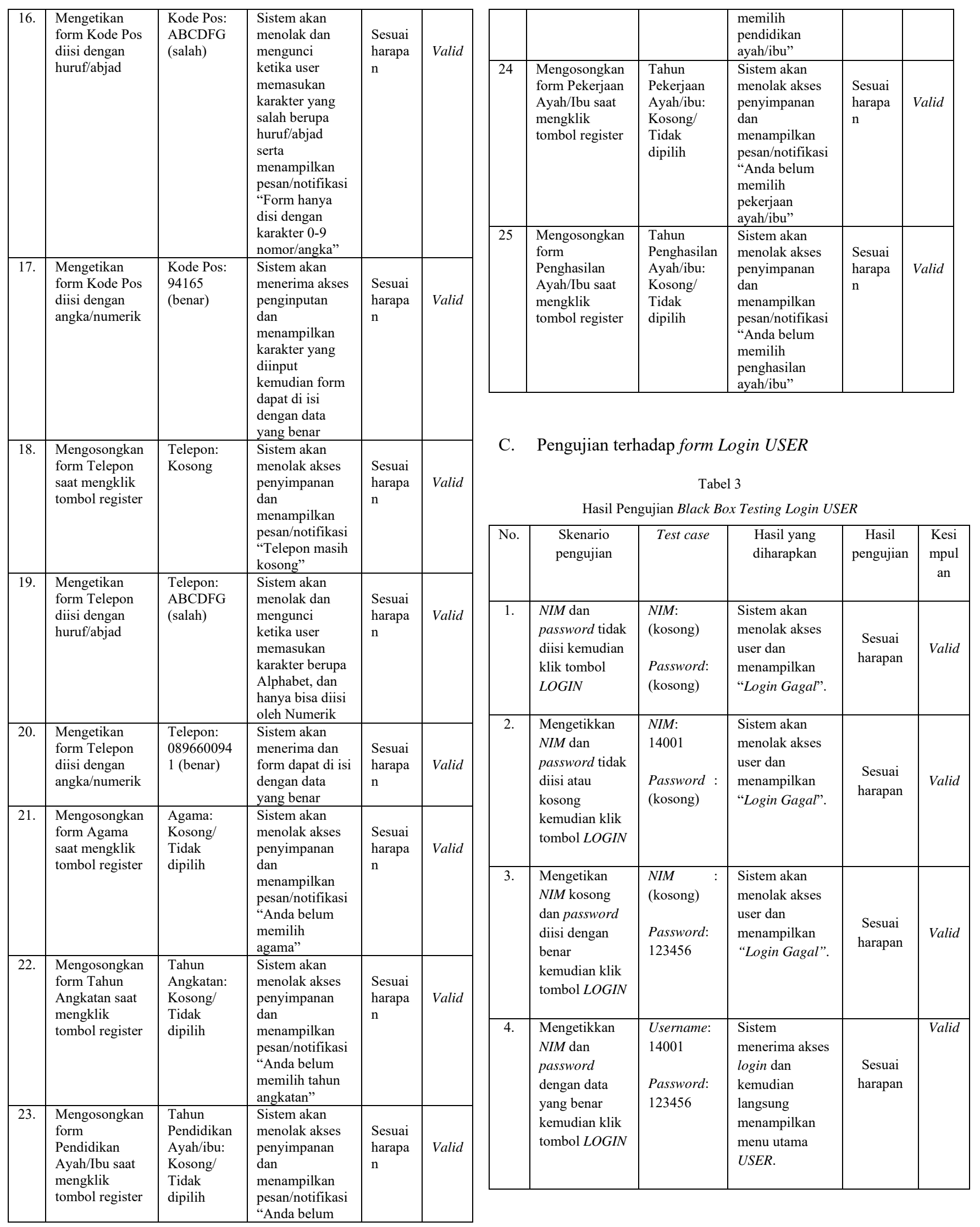




\section{KESIMPULAN DAN SARAN}

Sistem Informasi Akademik Mahasiswa merupakan sarana yang efektif dalam pendistribusian informasi yang lebih informatif di era digital. Kemudahan layanan akses yang tidak terbatas dalam waktu 24 jam memudahkan admin / staff akademik dalam mengelola jadwal kuliah, nilai, krs dan khs secara online. Memungkinkan mahasiswa tetap mendapatkan informasi meski berhalangan hadir ke kampus.

Melakukan sosialisasi kepada mahasiswa dan staff akademik dalam pengimplementasian sistem informasi akademik mahasiswa. Melakukan pengembangan pada sistem informasi akademik seiring dengan bertambahnya kebutuhan institusi seperti integrasi dengan pihak bank guna proses pembayaran SPP/admnistrasi. Meningkatkan sarana dan prasarana khususnya yang berhubungan dengan teknologi informasi

\section{REEFERENSI}

[1] Husda, Nur Elfi dan Wangdra, Yvone. 2016. Pengantar Teknologi Informasi Edisi Revisi. Jakarta: Baduose Media.

[2] Madcoms. 2016. Pemrograman PHP dan MySQL. Yogyakarta: Andi

[3] Kadir, Abdul. 2011. Buku Pintar jQuery dan PHP. Yogyakarta: MediaKom

[4] Rosa dan Shalahudin. 2014. Rekayasa Perangkat Lunak Terstruktur dan Berorientasi Objek. Bandung: Informatika

[5] Bakhri, S. 2015. Rancang Bangun Sistem Informasi Penjualan Sembako Menggunakan Model Waterfall ( Studi Kasus : Koperasi Karyawan PT. Frisian Flags). Jurnal Khatulistiwa Informatika, 3(1), $70-82$. 